(C) 1981. The Genetical Society of Great Britain

\title{
GENETIC VARIABILITY IN MUSCARI COMOSUM (LILIACEAE). I. A COMPARATIVE ANALYSIS OF CHROMOSOME POLYMORPHISMS IN SPANISH AND AEGEAN POPULATIONS
}

\author{
M. RUIZ-REJON* and JOSÉ L. OLIVER† \\ * Dpto. de Genética, Facultad de Ciencias, Universidad de Granada, Spain; \\ † Dpto. de Genética, C-15, Facultad de Ciencias, Universidad Autónoma de Madrid, \\ Madrid-34, Spain
}

Received 11.iii.81

\section{INTRODUCTION}

GARBARI $(1966,1969)$ has reported a stable structural polymorphism in populations of Italian Muscari comosum. This was for a pericentric inversion in the 2nd largest pair of chromosomes. The same polymorphism was subsequently seen by Bentzer (1972) and Bentzer and Ellmer (1975) in material from several Aegean Islands (Greece). These authors also reported a heteromorphism for the size of the chromosome concerned. A similar situation has since been noted in populations from Egypt (Bentzer, unpublished data, cited in Bentzer, 1972). This paper reports a cytological analysis of seven Spanish populations, in which the arrangement frequencies are compared with those present in the Aegean Islands.

\section{MATERIALS AND METHODS}

A total of 311 bulbs from seven Spanish populations (table 1) were collected during 1978,1979 , and 1980 . The bulbs chosen were usually

TABLE 1

Number of plants with the various cytotypes of chromosome 2

\begin{tabular}{|c|c|c|c|c|c|c|c|c|c|}
\hline \multirow[b]{2}{*}{ Key } & \multirow[b]{2}{*}{ Population } & \multirow[b]{2}{*}{ Sample size } & \multicolumn{7}{|c|}{ Cytotypes } \\
\hline & & & $+1+$ & $+/ \mathrm{i}$ & $\mathrm{i} / \mathrm{i}$ & $+1+1$ & $+/$ il & $i / /+1$ & $\mathrm{i} / \mathrm{il}$ \\
\hline GAR & Gargantilla (Madrid) & 100 & 44 & 30 & 4 & 7 & 8 & 6 & 1 \\
\hline $\mathrm{COL}$ & Colmenar (Málaga) & 50 & 26 & 16 & 1 & - & 4 & - & 3 \\
\hline SIL & Silleta (Granada) & 50 & 20 & 18 & 5 & 2 & 3 & 1 & 1 \\
\hline PAD & Padul (Granada) & 35 & 31 & 4 & - & - & - & - & - \\
\hline CAZ & $S^{a}$ Cázulas (Granada) & 18 & 10 & 4 & 2 & 1 & - & - & 1 \\
\hline MOL & El Molar (Madrid) & 18 & 10 & 6 & - & - & 2 & - & - \\
\hline $\mathrm{COZ}$ & Cozvijar (Granada) & 40 & 35 & 5 & - & - & - & - & - \\
\hline & Total & 311 & 176 & 83 & 12 & 10 & 17 & 7 & 6 \\
\hline
\end{tabular}

more than one meter apart. Young inflorescences were fixed in ethanol: acetic acid $(3: 1)$. The total size and arm proportion of the first and second chromosome pairs were measured in five metaphase cells from the root tips of each bulb. The meiotic behaviour of PMCs was analysed by staining young anthers in acetic-carmine. 


\section{Results}

\section{(i) Cytogenetic analysis}

All the bulbs analysed had the diploid value typical for this species with $2 n=18$ (fig. 1). Four types of chromosome 2 were present and these agree with those described by Bentzer and Ellmer (1975) in Aegean populations: Normal (+) (fig. 1), inversion type (i) (fig. 2), inversion with extra long arm (il) (fig. 3), and normal with extra long arm (+l) (fig. 4). These four types have the same r-values and proportions reported by Bentzer (1972) and Bentzer and Ellmer (1975). Because the centromere position differs without affecting the chromosome size, the inversion chromosome type probably originated by a pericentric inversion (Bentzer, 1972). Although a centric transposition cannot be excluded, for the purpose of this paper it may be regarded as an inversion rearrangement. This chromosome pair shows a normal meiotic behaviour in both homozygotes $(+/+$ or $\mathrm{i} / \mathrm{i})$. In some (20 per cent) of the diakinesis cells from individuals carrying a heterozygous duplication (i.e., +1 or il) autosynapsis of the distal part of the longer chromosome is found (fig. 5).

\section{(ii) Chromosome variability in Spanish populations}

The number of plants with the various combinations of chromosome 2 , and the sample size in each population, are shown in table 1. In all seven populations the + chromosome is the most frequent, but the i type is present in substantial proportions in all except for PAD and $\mathrm{COZ}$ populations. The +1 and il chromosomes are found in low frequencies in GAR, SIL, and CAZ, while only the il type is present in the COL and MOL populations. All the Spanish populations lack homozygotes for the extra long arm (i.e., combinations $+1 /+1$, il/il, or $+1 /$ il).

\section{(iii) A comparison of the Spanish and Aegean populations}

Our data from the seven Spanish populations of $M$. comosum are combined with those of Bentzer and Ellmer (1975) on six Aegean populations in table 2. An estimate of the degree of chromosome differentiation for all populations is possible through the use of the distance statistic of Prevosti (1974) and Prevosti et al. (1975). This allows one to construct a distance matrix and from this the dendrogram shown in the fig. 6 was obtained by a single-linkage cluster analysis (Davies, 1971). We have also analyzed the total inversion frequencies, the observed inversion heterozygosity, and the means for each geographical area (table 3).

\section{Discussion}

The populations of Muscari comosum from the Iberian Peninsula (the western end of its Mediterranean distribution) carry the same chromosome variants which Bentzer and Ellmer (1975) reported from the Aegean Islands (central zone). As Bentzer (1972) indicated, one of these is probably a pericentric inversion; on the basis of its meiotic behaviour the other is probably a segmental duplication. If the rearrangements involved in this 


\section{Plate I}
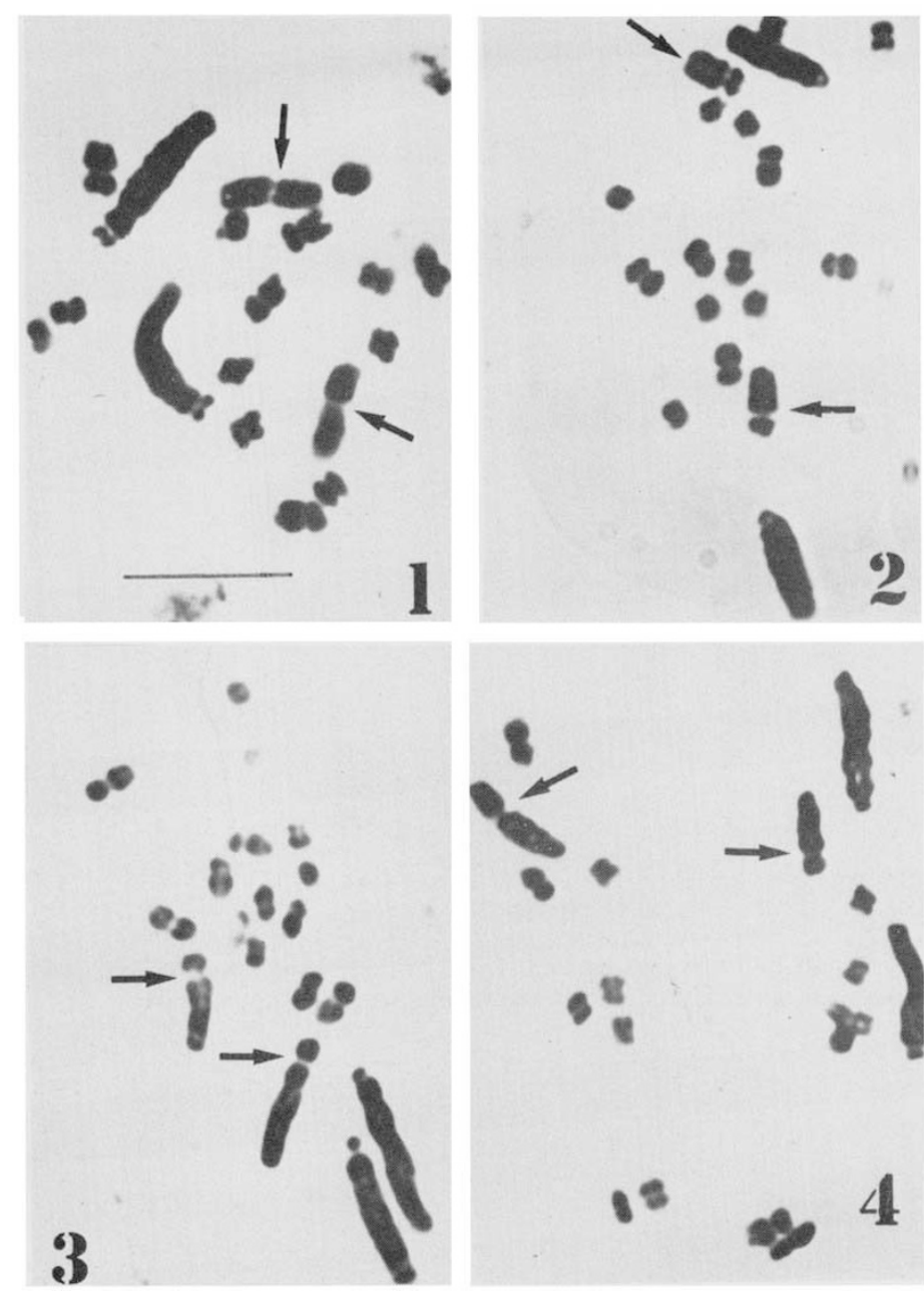

FIGs. 1-4.-Metaphase plates from $+/+$ (Fig. 1), i/i (Fig. 2), i/il (Fig. 3), and $+/+1$ (Fig.

4 ) individuals. Arrows indicate the second chromosome pair. Scale equals $5 \mu$. 


\section{Plate II}
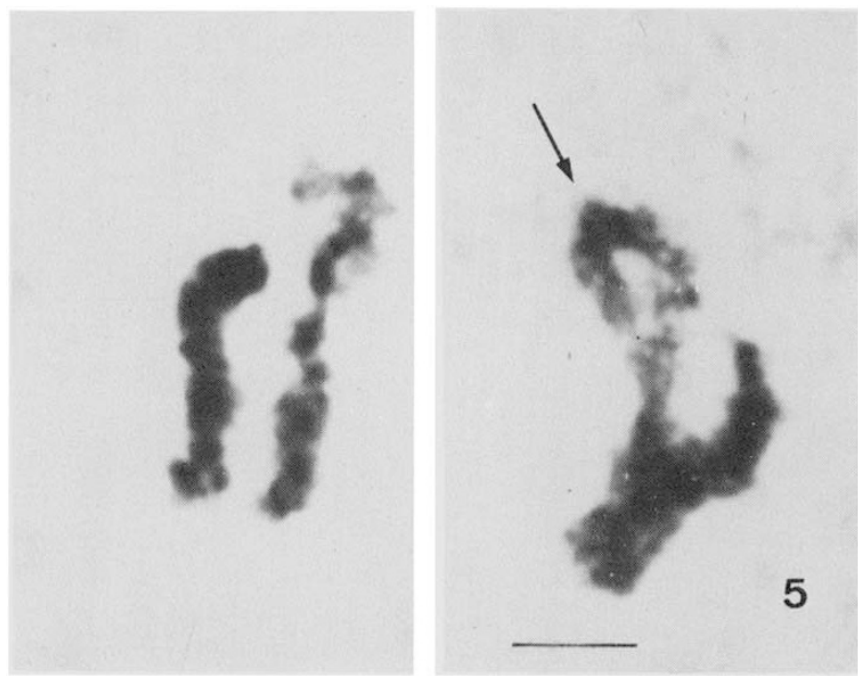

FIG. 5.-Structural heterozygote bivalent from il/i individual. Normal synapsis (left) and autosynapsis (right). Arrow indicates autosynapsis. Scale equals $2 \mu$. 
TABLE 2

Arrangement frequencies in Spanish and Aegean populations

\begin{tabular}{|c|c|c|c|c|c|}
\hline \multirow{3}{*}{$\begin{array}{l}\text { Population } \\
\text { (a) Spain }\end{array}$} & \multirow[b]{2}{*}{ Sample size } & \multicolumn{4}{|c|}{ Arrangements } \\
\hline & & + & $\mathrm{i}$ & non-1 & 1 \\
\hline & & & & \\
\hline GAR & 200 & 0.730 & $0 \cdot 270$ & $0 \cdot 890$ & $0 \cdot 110$ \\
\hline $\mathrm{COL}$ & 100 & $0 \cdot 720$ & $0 \cdot 280$ & 0.930 & 0.070 \\
\hline SIL & 100 & $0 \cdot 660$ & $0 \cdot 340$ & 0.930 & 0.070 \\
\hline PAD & 70 & 0.943 & 0.057 & 1.000 & - \\
\hline $\mathrm{CAZ}$ & 36 & 0.722 & 0.278 & 0.944 & 0.056 \\
\hline MOL & 36 & 0.778 & $0 \cdot 222$ & 0.944 & 0.056 \\
\hline $\mathrm{COZ}$ & 80 & 0.938 & 0.062 & 1.000 & - \\
\hline \multicolumn{6}{|l|}{ (b) Greece } \\
\hline 600 (Kithnos) & 36 & 0.417 & 0.583 & 0.972 & 0.028 \\
\hline 601 (Kithnos) & 144 & 0.708 & 0.292 & 0.944 & 0.056 \\
\hline 602 (Kithnos) & 106 & 0.613 & 0.387 & 0.858 & $0 \cdot 142$ \\
\hline 603 (Rodhos) & 84 & $0 \cdot 464$ & 0.536 & 0.940 & 0.060 \\
\hline 604 (Rodhos) & 52 & 0.481 & $0 \cdot 519$ & 0.865 & 0.135 \\
\hline 605 (Kithnos) & 74 & $0 \cdot 703$ & $0 \cdot 297$ & 0.919 & 0.081 \\
\hline
\end{tabular}

study are unique in origin, their distribution over such a wide range can only be attributed to the migration of either individuals or gametes.

Bentzer and Ellmer (1975) explained the different frequencies of chromosome types found in the Aegean Islands in terms of genetic drift. From our data we would argue that adaptive and historical factors, related to the colonization process, may be also important to explain the total geographical distribution of both chromosome rearrangements.

Like Bentzer and Ellmer (1975) we have not found homozygous individuals for the extra long arm (i.e., $\mathrm{il} / \mathrm{il},+1 /+1$, or $+1 / \mathrm{il})$. We appreciate that the low frequencies of +1 and il chromosomes produce a very low probability of finding them together in one plant. Nevertheless, when a Student $t$-test with the angular transformation of the data (Sokal and Rohlf, 1969) is applied to the Spanish population from GAR, which has the highest sample size, a statistically significant deficiency of duplication homozygotes is found $\left(t_{s}=2 \cdot 20 ; P: 0 \cdot 05-0 \cdot 01\right)$. Likewise, if the expected frequencies of chromosome types, as computed from the rearrangement frequencies (table 2), are compared with the observed frequencies in the Spanish population from COL, a statistically significant deficiency of +1 chromosomes is found $\left(t_{s}=3.20 ; P: 0.01-0.001\right)$. There are also significantly fewer il chromosomes in the population 601 from Kithnos than is expected $\left(t_{s}=2 \cdot 18 ; P: 0.05-0 \cdot 01\right)$. Therefore, it seems that the chromosomes carrying the extra material may be selected against.

On the other hand, from the analysis of the dendrogram (fig. 6), we can conclude that:

(1) If population 600 is discounted, the populations from Kithnos tend to cluster with the Spanish ones and appear more distantly related to the populations from Rodhos. The higher similarity between Spain and Kithnos is due to their lower inversion frequencies. The Rodhos collection, on the other hand, shows a higher frequency of inversion chromosomes. When inversion frequencies in Aegean and Spanish populations are compared 


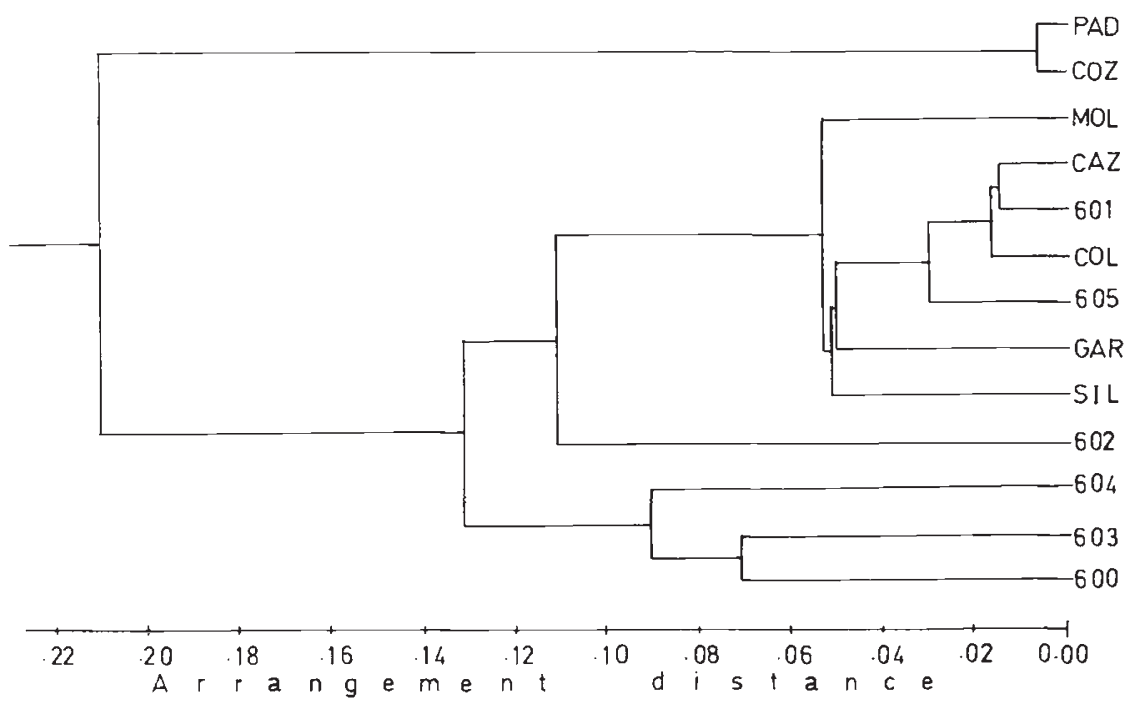

FIG. 6.-Dendrogram showing the relationships between Spanish and Aegean populations of $M$. comosum, as inferred from their arrangement distance matrix.

(table 3), striking differences are found. The mean inversion frequencies are higher in Rodhos, intermediate in Kithnos, and lower in the Iberian Peninsula. More samples from other geographical areas need to be analyzed to determine whether there is any clinal relationship which relates to colonization and expansion of $M$. comosum.

(2) The two Spanish populations from PAD and COZ appear as the most differentiated ones. These populations offer an interesting opportunity to test the respective roles played by natural selection and genetic drift in maintaining the inversion polymorphism in question. Both Spanish populations have the lowest inversion frequencies (table 3 ). Their heterozygosity values (table 3 ) are also significantly lower than those present in the remaining Spanish and Aegean populations. Furthermore, the two Spanish

TABLE 3

Total inversion frequencies, observed inversion heterozygosities and means for each geographical area in Mediterranean populations of $\mathrm{M}$. comosum

\begin{tabular}{cccccc}
\multirow{5}{*}{ Rodhos } & Population & $\begin{array}{c}\text { Inversion } \\
\text { frequency }\end{array}$ & Mean & $\begin{array}{c}\text { Observed } \\
\text { heterozygosity }\end{array}$ & Mean \\
& 603 & 0.54 & $0.53 \pm 0.01$ & 0.37 & $0.48 \pm 0.11$ \\
& 604 & 0.52 & & 0.58 & \\
Kithnos & 600 & 0.58 & & 0.72 & \\
& 601 & 0.29 & $0.39 \pm 0.07$ & 0.39 & $0.56 \pm 0.07$ \\
& 602 & 0.38 & & 0.62 & \\
& 605 & 0.30 & & 0.49 & \\
& GAR & 0.27 & & 0.44 & \\
& COL & 0.28 & & 0.40 & \\
& SIL & 0.34 & & 0.44 & $0.31 \pm 0.06$ \\
& PAD & 0.06 & $0.22 \pm 0.04$ & 0.13 & \\
& CAZ & 0.28 & & 0.22 &
\end{tabular}


populations show characteristics which are typical of an ecological border, namely: recent colonization (they were cultivated fields ten years ago), low population size, and differential edaphic conditions.

The PAD and $\mathrm{COZ}$ populations have a normal level of allozyme polymorphism, as compared with the remaining Spanish populations (Pascual et al., in preparation). In both PAD and COZ there is therefore no restriction of genic variability. This constitutes further support for the well established conclusion that allozyme polymorphisms show more uniform geographical distribution than chromosome polymorphisms (Ayala et al., 1971; González-Duarte et al., 1973; Powell, 1973; Saura and Lakovaara, 1973; Lewontin, 1974).

One final conclusion emerges from our data. If the low inversion heterozygosities from $\mathrm{PAD}$ and $\mathrm{COZ}$ populations are maintained by genetic drift (e.g., founder effect), then the normal level of allozyme variability is difficult to explain. On the other hand, if the low inversion heterozygosities from these two populations are maintained by natural selection, the existence of a normal level of allozyme polymorphism in three particular enzymes can be readily explained.

In conclusion, although genetic drift cannot be rejected, we think that the interaction between adaptive and historical factors, related to the colonization process, have played the major role in determining the geographical distribution of the two coupled stable chromosome polymorphisms present in Muscari comosum.

Acknowledgements.-We wish to thank Dr G. M. Hewitt, Dr B. John, Dr A. Prevosti, and Dr J. Rubio for their perceptive criticism of the manuscript.

\section{REFERENCES}

AYAlA, F. J., POWELL, J. R., AND DOBZHANSKY, TH. 1971. Polymorphisms in Continental and Island Populations of Drosophila willistoni. Proc. Natl. Acad. Sci. U.S.A., 68, 2480-2483.

BENTZER, B. 1972. Variation in the chromosome complement of Leopoldia comosa (L.) Parl. (Liliaceae). Bot. Notiser, 125, 406-418.

BENTZER, B., AND ELLMER, M. 1975. A case of stable chromosomal polymorphism in Leopoldia comosa (Liliaceae). Hereditas, 81, 127-132.

DAvies, R. G. 1971. Computer Programming in Quantitative Biology. Academic Press, New York.

GARBARI, F. 1966. Contributo allo studio citologico dei Muscari italiani. Caryologia, 19, 419-428.

GARBARI, F. 1969. Nuove osservazioni citologiche sui generi Muscari e Leopoldia. Gior. Bot. Ital., 103, $1-9$.

GonZAlez-DUARTE, R., GONZALEZ-IZQUiERDo, M. C., AND PREvosti, A. 1973. Polymorphism for esterases and alcohol dehydrogenases in natural populations of Drosophila subobscura. Atti Acad. Sci. Ist. Bologna, 261, serie IV, 63-70.

LEWONTIN, R. C. 1974. The Genetics Basis of Evolutionary Change. Columbia, New York. POWELl, J. R. 1973. Chromosomal versus protein polymorphism in Drosophila. Genetics, $74, \mathrm{~s} 217$.

Prevosti, A. 1974. La distancia genética entre poblaciones. Miscellanea Alcobé. Public. Univ. Barcelona, 109-118.

PREVOSTI, A., OCAÑA, J., AND ALONSO, G. 1975. Distances between populations of Drosophila subobscura, based on chromosome arrangement frequencies. Theoret. Appl. Genetics, 45, 231-241.

SAURA, A., AND LAKOVAARA, S. 1973. Genetic variation in central and marginal populations of Drosophila subobscura. Hereditas, 75, 33-46.

SOKAL, R. R., AND ROHLF, F. J. 1969. Biometry. W. H. Freeman, San Francisco. 